\title{
Modal Analysis of Grid-Connected Doubly Fed Induction Generators
}

\author{
Francoise Mei, Student Member, IEEE, and Bikash Pal, Senior Member, IEEE
}

\begin{abstract}
This paper presents the modal analysis of a gridconnected doubly fed induction generator (DFIG). The change in modal properties for different system parameters, operating points, and grid strengths are computed and observed. The results offer a better understanding of the DFIG intrinsic dynamics, which can also be useful for control design and model justification.
\end{abstract}

Index Terms-Doubly fed induction generator, eigenvalue analysis, nonlinear dynamic model, small-signal stability.

\section{INTRODUCTION}

$\mathbf{T}$ RADITIONALLY, the oscillatory behavior of power systems has been dominated by the electromechanical interactions between the synchronous generators through the network. As the generation of power from wind energy conversion systems (WECS) using induction generators is increasing significantly, it is important to assess the impact of this type of asynchronous generation on the system stability and vice versa.

The dynamic behavior of the doubly fed induction generator (DFIG) has been investigated by various authors. The majority of these studies are based on time-domain simulations to show the impact on power system dynamics [1], [2], the performance of decoupled control and maximum power tracking [3], the response to grid disturbances [4], the fault ridethrough behavior [5], the control methods to make the DFIG behave like a synchronous generator [6], etc. Time-domain studies offer a direct appreciation of the dynamic behavior in terms of visual clarity. However, they are not able to identify and quantify the cause and nature of interactions and problems. This complementary information can be obtained with eigenvalue studies.

Such studies have been carried out earlier for fixed-speed induction generators in WECS applications [7] and variablespeed induction machines in slip-energy recovery drive applications [8], [9]. In this paper, the grid-connected DFIG is studied. The single-machine infinite-bus (SMIB) approach is followed.

The paper is organized as follows. In Section II, modeling considerations are briefly reviewed. In Section III, the base-case analysis is given, and the typical DFIG small-signal behavior is explained. In Sections IV-VII, the eigenvalue loci for different machine parameters, operating points, and grid strength are examined, and the conditions for which stator transients can be neglected are determined. Section VIII presents the conclusion.

Manuscript received October 6, 2005; revised May 4, 2006. This work was supported by the Engineering and Physical Sciences Research Council under Grant GR/S28082/01. Paper No. TEC-00351-2005.

The authors are with the Department of Electrical Engineering, Imperial College London, London SW7 2BT, U.K. (e-mail: francoise.mei@imperial.ac.uk; b.pal@imperial.ac.uk).

Digital Object Identifier 10.1109/TEC.2006.881080

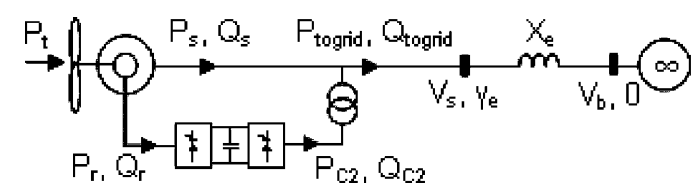

Fig. 1. Grid-connected WECS with DFIG.

\section{MOdELING}

The studied SMIB system is shown in Fig. 1. The DFIG transforms the input turbine power $P_{t}$ into electrical power. The produced stator power $P_{s}$ is always positive. The rotor power $P_{r}$ can be both positive and negative due to the presence of the back-to-back converter. This allows the machine to operate at both sub- and supersynchronous speeds [3].

\section{A. Turbine}

The turbine is formed by the blades and the hub. Its role is to capture the kinetic energy of the wind and transfer it to the generator in the form of mechanical power.

The dynamics of the airflow around the blades can be modeled using, e.g., blade element methods or computational fluid dynamic methods [10]. In general, these detailed models are used for the purpose of turbine design and mechanical testing only.

For stability studies, an algebraic model is used, and the dynamics related to turbine, yaw system, and tower can be ignored [11], [12]. The algebraic model reflects the fact that the captured power is only a portion of available wind power (theoretical maximum $=$ Betz limit).

In this paper, the input mechanical power is assumed constant. In other words, it is assumed that the wind speed and blade pitch angle do not change during the period of study. This simplifies the analysis by allowing the observation of the modes inherent to the generator.

\section{B. Drive Train}

In power system studies, drive trains are modeled as a series of rigid disks connected via massless shafts. For small-signal analysis of synchronous generators (SG) in conventional power plants, the one-mass or lumped-mass model is used because the drive train behaves as a single equivalent mass (the mode of interest is nontorsional, with nearly equal participation of all inertias) [13]. This results from the fact that the mechanical stiffness (between the generator, turbine and between adjacent turbine segments) is much higher than the equivalent electrical stiffness (between the generator and the infinite bus) [7]. In this case, the mode of interest is often referred interchangeably as "system mode," "nontorsional-mode," or "electromechanical mode" [13]. 
When it comes to DFIG in wind power plants, the mechanical parameters are such that those terms cannot be used interchangeably. The presence of a gearbox makes the shaft more slender, resulting in a mechanical stiffness of the same order as the equivalent electrical stiffness [7], [14]. The lower shaft stiffness combined with the fact that the generator is relatively much lighter than the turbine results in a dynamic behavior where there is no "system mode." In other words, there is no mode for which the drive train behaves as a single equivalent mass.

As a result, a multimass drive train must be considered for small-signal stability studies of WECS with DFIG. In general, it is sufficient to consider the two-mass model (one for the turbine, the other for the generator) because the modes associated with the blades and hub are either well damped or out of the frequency range of interest [7].

The dynamic equations are obtained from Newton's equations of motion for each mass (rotational speed) and shaft (torsion or twist angle) [2]

$$
\begin{aligned}
2 H_{t} \frac{d \omega_{t}}{d t} & =\frac{P_{t}}{\omega_{t}}-T_{\mathrm{sh}} \\
\frac{1}{\omega_{\mathrm{elB}}} \frac{d \theta_{t w}}{d t} & =\omega_{t}-\omega_{r} \\
2 H_{g} \frac{d \omega_{r}}{d t} & =T_{\mathrm{sh}}-T_{e}
\end{aligned}
$$

where $\omega_{t}$ and $\omega_{r}$ [per unit (p.u.)] are the turbine and generator speeds, respectively; $\theta_{\mathrm{tw}}$ [rad] is the shaft twist angle; $H_{t}$ and $H_{g}[\mathrm{~s}]$ are the turbine and generator inertias, respectively; $\omega_{\mathrm{elB}}$ [rad/s] is the electrical base speed; $P_{t}$ [p.u.] is the turbine input power (here assumed as constant); and $T_{\mathrm{sh}}$ and $T_{e}$ [p.u.] are the shaft and generator torques, respectively

$$
\begin{aligned}
T_{\mathrm{sh}} & =k \theta_{\mathrm{tw}}+c\left(\frac{d \theta_{\mathrm{tw}}}{d t}\right) \\
T_{e} & =\left(\frac{e_{\mathrm{qs}}^{\prime}}{\omega_{s}}\right) i_{\mathrm{qs}}+\left(\frac{e_{0 \mathrm{ds}}^{\prime}}{\omega_{s}}\right) i_{\mathrm{ds}}
\end{aligned}
$$

where $k$ [p.u./el.rad] and $c$ [p.u.s/el.rad] are the shaft stiffness and damping coefficients, respectively; $e_{\mathrm{qs}}^{\prime}, e_{\mathrm{ds}}^{\prime}, i_{\mathrm{qs}}$, and $i_{\mathrm{ds}}$, and $\omega_{s}$ are defined in Section II-C.

\section{Generator}

The dynamic equations describing the DFIG are obtained by transforming the machine three-phase voltage equations into a synchronously rotating frame, referred to as the dq frame [3]. In this paper, the abc-dq transformation is power invariant with the $d$-axis leading. For stability studies, the generators are usually modeled as an equivalent voltage source based on transient impedance [13]. This is done by defining the variables

$$
\begin{aligned}
& e_{\mathrm{qs}}^{\prime}=K_{\mathrm{mrr}} \omega_{s} \psi_{\mathrm{dr}} \\
& e_{\mathrm{ds}}^{\prime}=-K_{\mathrm{mrr}} \omega_{s} \psi_{\mathrm{qr}} \\
& L_{s}^{\prime}=L_{\mathrm{ss}}-\frac{L_{m}^{2}}{L_{\mathrm{rr}}} \\
& T_{r}=\frac{L_{\mathrm{rr}}}{R_{r}}
\end{aligned}
$$

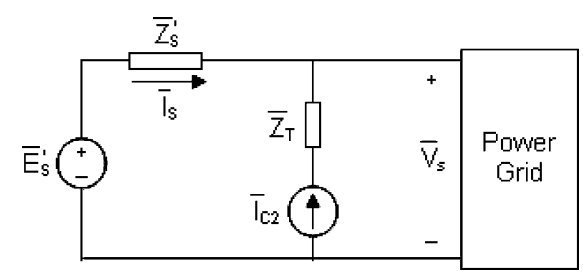

Fig. 2. DFIG equivalent model for stability studies.

where $e_{\mathrm{qS}}^{\prime}$ and $e_{\mathrm{ds}}^{\prime}$ [p.u.] are the equivalent internal $q$ - and $d$-axis voltages, respectively; $\psi_{\mathrm{qr}}$ and $\psi_{\mathrm{dr}}$ [p.u.] are the rotor $q$ - and $d$ fluxes, respectively; $K_{\mathrm{mrr}}=L_{m} / L_{\mathrm{rr}}$; and $L_{\mathrm{ss}}, L_{\mathrm{rr}}$, and $L_{m}$ [p.u.] are the stator, rotor, and mutual inductances, respectively. $R_{r}$ [p.u.] is the rotor resistance.

For balanced and unsaturated conditions, the corresponding p.u. DFIG model is

$$
\begin{aligned}
& \frac{\omega_{s} L_{s}^{\prime}}{\omega_{\mathrm{el}}} \frac{d i_{\mathrm{qs}}}{d t}=-R_{1} i_{\mathrm{qs}}+\omega_{s} L_{s}^{\prime} i_{\mathrm{ds}}+\frac{\omega_{r}}{\omega_{s}} e_{\mathrm{qs}}^{\prime}-\frac{1}{T_{r} \omega_{s}} e_{\mathrm{ds}}^{\prime} \cdots \\
& \cdots-v_{\mathrm{qs}}+K_{\mathrm{mrr}} v_{\mathrm{qr}} \\
& \frac{\omega_{s} L_{s}^{\prime}}{\omega_{\mathrm{el}}} \frac{d i_{\mathrm{ds}}}{d t}=-\omega_{s} L_{s}^{\prime} i_{\mathrm{qs}}-R_{1} i_{\mathrm{ds}}+\frac{1}{T_{r} \omega_{s}} e_{\mathrm{qs}}^{\prime}+\frac{\omega_{r}}{\omega_{s}} e_{\mathrm{ds}}^{\prime} \cdots \\
& \cdots-v_{\mathrm{ds}}+K_{\mathrm{mrr}} v_{\mathrm{dr}} \\
& \frac{1}{\omega_{\mathrm{el}}} \frac{d e_{\mathrm{qs}}^{\prime}}{d t}=R_{2} i_{\mathrm{ds}}-\frac{1}{T_{r} \omega_{s}} e_{\mathrm{qs}}^{\prime}+\left(1-\frac{\omega_{r}}{\omega_{s}}\right) e_{\mathrm{ds}}^{\prime}-K_{\mathrm{mrr}} v_{\mathrm{dr}} \\
& \frac{1}{\omega_{\mathrm{el}}} \frac{d e_{\mathrm{ds}}^{\prime}}{d t}=-R_{2} i_{\mathrm{qs}}-\left(1-\frac{\omega_{r}}{\omega_{s}}\right) e_{\mathrm{qs}}^{\prime}-\frac{1}{T_{r} \omega_{s}} e_{\mathrm{ds}}^{\prime}+K_{\mathrm{mrr}} v_{\mathrm{qr}}
\end{aligned}
$$

where $i_{\mathrm{qs}}$ and $i_{\mathrm{ds}}$ [p.u.] are the stator $q$ - and $d$-axis currents, respectively; $\omega_{s}$ [p.u.] is the synchronous speed; $\omega_{\mathrm{el}}=\omega_{\mathrm{elB}} \omega_{s} ; R_{s}$ [p.u.] is the stator resistance; and $R_{1}=R_{s}+R_{2}$ and $R_{2}=$ $K_{\mathrm{mrr}}^{2} R_{r}$.

The generator has three dynamic parts: stator electrical (10), (11); rotor electrical (12), (13); and rotor mechanical (3). For stability studies of conventional SG, stator transients are neglected [13]. Here, they are included so that the validity of this assumption can be checked.

The DFIG equivalent model for stability studies is shown in Fig. 2. The variables with an upperline are complex values with the real and imaginary components equal to the $q$ - and $d$-axis components, respectively (e.g., the stator current is $\bar{I}_{s}=i_{\mathrm{qs}}+$ $j i_{\mathrm{ds}}$ ). The current source $\bar{I}_{C 2}$ represents the bidirectional current from the grid-side converter, as explained in Section II-D.

\section{Converter}

The ac-dc-ac converter comprises of two pulse width modulation inverters connected back-to-back via a dc link. The rotorside converter operates as a controlled voltage source since it injects an ac voltage at slip frequency to the DFIG rotor. The grid-side converter operates as a controlled current source since it maintains the dc-link voltage constant and injects an ac current at grid frequency to the network [3]. 
The ac voltage of the rotor-side converter depends on the control objectives. For grid-connected WECS applications, a sensible choice is to impose a constraint for maximum power capture (equivalent to airgap power, electromagnetic torque, or speed constraint) and another for the voltage control (reactive power constraint). These two objectives determine the DFIG rotor voltage

$$
\bar{V}_{r}=\bar{V}_{r}^{\mathrm{ref}} \quad \text { so that } \quad T_{e}=T_{e}^{\mathrm{ref}}\left(\omega_{r}\right), \quad V_{s}=V_{s}^{\mathrm{ref}} .
$$

The control objectives are usually formulated in the converter dq-axis with decoupled real and reactive power control. A convenient way to implement the active power control for the rotor-side converter is to construct a reference torque as a function of the generator speed [3]. By doing so, the generator speed control is incorporated, and the requirement of wind-speed measurement is avoided.

For the grid-side converter, the control has to be coordinated so that the dc-link voltage is constant and the desired sharing of reactive power with stator is achieved. The reactive power sharing between the stator- and grid-side converters can be chosen arbitrarily. For minimum converter rating, as assumed in this paper, no sharing is done, and the reactive power delivered to the grid comes only from the stator. Hence, the grid-side converter ac current is such that the active power injected to the mains matches that of the rotor-side converter at unity power factor

$$
\bar{I}_{C 2}=\bar{I}_{C 2}^{\mathrm{ref}} \quad \text { so that } \quad P_{C 2}=P_{r}, \quad Q_{C 2}=0 .
$$

By assuming the current control sufficiently fast and accurate, the dc-link voltage can be considered as constant, and no dynamic model is required for the dc-link capacitor. The role of the dc-link capacitor is to act as a voltage source to the converters. For drive applications using a diode rectifier on the rotor side, the dynamics of the dc-link components may not be ignored because of the dc-energy storage mechanism, bulkier dc components, and lesser control capability. For back-to-back converters, however, an adequate control eliminates the need for storage in the dc-link and ensures a practically constant dc voltage [15].

In this paper, it is assumed that the ac-dc-ac converter is made of lossless components, and the switching dynamics are not considered (not in the range of interest). The analysis is done for open loop, i.e., the rotor voltage remains constant at its initial value. Closed-loop controllers are not included because the eigenvalues displacement they introduce depends very much on the control scheme and gains, so that the conclusions regarding the small-signal behavior will not be a true reflection of the DFIG dynamics.

\section{E. External Grid}

To complete the model of the grid-connected DFIG, two more equations are required, namely the equations of the active and reactive power exchange between the grid and the generator.

In this paper, the external system is the infinite bus. Hence, the network algebraic equations are simply

$$
P_{\text {togrid }}=\frac{V_{s} V_{b} \sin \gamma_{e}}{X_{e}}
$$

$$
Q_{\mathrm{togrid}}=\frac{V_{s}^{2}-V_{s} V_{b} \cos \gamma_{e}}{X_{e}}
$$

where the active and reactive powers delivered by the generator are $P_{\text {togrid }}=P_{s}+P_{C 2}$ and $Q_{\text {togrid }}=Q_{s}+Q_{C 2}$ with $P_{C 2}=$ $P_{r}$ and $Q_{C 2}=0 ; V_{s}$ is the DFIG stator voltage magnitude; $V_{b}$ and $\gamma_{e}$ are the magnitude and angle of the infinite bus voltage; and $X_{e}$ is the reactance of the external line.

\section{Modal Analysis-Base Case}

\section{A. Initial Conditions}

Initialization of the power system model is the starting point for both time-domain and frequency-domain analyses. This is done in two steps. First, the loadflow calculation is done in order to obtain the voltage magnitude, voltage angle, and injected active and reactive powers at each bus. Then, with the obtained loadflow solution, the generator is initialized by solving its set of differential algebraic equations (DAE) with all time derivatives set equal to zero.

\section{B. Linearized Dynamic Model}

The mathematical model of a power system can be written as a set of DAE

$$
\begin{aligned}
\frac{d x}{d t} & =f(x, z, u) \\
0 & =g(x, z, u)
\end{aligned}
$$

where $x, z$, and $u$ are the state, algebraic, and input variables; $f$ and $g$ are the vectors of differential and algebraic equations, respectively. In small-signal analysis studies, (18) and (19) are linearized by a Taylor series expansion around an operating point $\left(x_{0}, z_{0}, u_{0}\right)$. Neglecting the terms of order two and above, and eliminating the algebraic variable $z$, the system state matrix is obtained as

$$
A_{\mathrm{sys}}=\left[\frac{\partial f}{\partial x}-\frac{\partial f}{\partial z}\left(\frac{\partial g}{\partial z}\right)^{-1} \frac{\partial g}{\partial x}\right]_{x_{0}, z_{0}, u_{0}} .
$$

The system dynamics is studied by examining the eigenvalues of $A_{\mathrm{sys}}$, as shown in Section IV. In this paper, $x=\left[\begin{array}{lllllll}i_{\mathrm{qs}} & i_{\mathrm{ds}} & e_{\mathrm{qs}}^{\prime} & e_{\mathrm{ds}}^{\prime} & \omega_{r} & \theta_{\mathrm{tw}} & \omega_{t}\end{array}\right]^{\prime}, z=\left[\begin{array}{ll}V_{s} & \gamma_{e}\end{array}\right]^{\prime}, u=$ $\left[\begin{array}{lll}v_{\mathrm{qr}} & v_{\mathrm{dr}} & P_{t}\end{array}\right]^{\prime}, f$ is contained in (10)-(13) and (1)-(3), and $g$ is contained in (16) and (17).

\section{Base-Case Modes}

The SMIB system shown in Fig. 1 is studied. In the base case, the terminal voltage is 1 p.u., the total active power is 1 p.u., and the speed is at its rated value, which is assumed to be the synchronous speed. It is also assumed that the DFIG is directly connected to the infinite bus, i.e., the reactive power output is zero, and the terminal voltage remains constant. The effect of finite grid strength is investigated later.

The base-case eigenvalues and their labeling are shown in Table I(A). The modal oscillation frequency, damping ratio, and participation factors are shown in Table I(B). The labeling of 
TABLE I

BASE-CASE MODES

(A) Eigervalues $\lambda$ ard nature of the mode

\begin{tabular}{|l|c|l|}
\hline & $h_{=} \mathbf{\sigma} \pm \mathbf{j} \boldsymbol{j}$ & Nature of the Mode \\
\hline$h_{\mathbf{1}}$ & $-0.31 \pm \mathrm{j} 3.38$ & Mecharical mode \\
$h_{2}$ & $-8.01 \pm \mathrm{j} 63.57$ & Electro-mecharical mode \\
$h_{\mathbf{3}}$ & $-16.16 \pm \mathrm{j} 313.31$ & Stator mode \\
$h_{\mathbf{4}}$ & -17.44 & Non-oscillating mode \\
\hline
\end{tabular}

(B) Oscillation frequency $\mathrm{f}_{\mathrm{osc}}[\mathrm{Hz}]$, darnping ratio $\zeta$ and participation factors

\begin{tabular}{|c|c|c|c|c|c|c|c|c|c|}
\hline & $\mathbf{f}_{\text {osit }}$ & $\zeta$ & Piqus & Pids & $P_{\text {equs' }}$ & Peds' & Por & Potw & Pot \\
\hline$h_{1}$ & 0.54 & 0.092 & 00 & .00 & .00 & .01 & 00 & .49 & .50 \\
\hline$h_{2}$ & 10.12 & 0.125 & .02 & .01 & .01 & (47. & .46 & .01 & .00 \\
\hline$\lambda_{3}$ & 49.86 & 0.052 & .48 & .46 & .02 & .03 & .00 & .00 & 00 \\
\hline 24 & 0 & 1 & .00 & .01 & .98 & .01 & 00 & .00 & 100 \\
\hline
\end{tabular}

the modes is determined by observing the participation factors, as explained later.

The base case has four stable modes, three of which are oscillating. The participation factors show the physical nature of the modes: $\lambda_{1}$ is a mechanical mode associated with the turbine and shaft dynamics (turbine speed and torsion angle); $\lambda_{2}$ is an electromechanical mode associated with the rotor electrical and mechanical dynamics (q-axis flux and generator speed); $\lambda_{3}$ is an electrical mode associated with the stator dynamics; and $\lambda_{4}$ is a nonoscillating mode associated with the rotor electrical dynamics (d-axis flux). The participation factors also show that the modes are decoupled since a particular state variable participates significantly in only one of the modes.

The mechanical mode is the dominant mode. It has a very low frequency $(\sim 0.5 \mathrm{~Hz})$ with a reasonable damping ratio $(\sim 10 \%)$. The electromechanical mode has a higher frequency $(\sim 10 \mathrm{~Hz})$ and a slightly better damping ratio. The stator mode has the lowest damping ratio. However, its time constant is small (large real-part magnitude) and its frequency is much higher and out of the range of interest.

The three oscillating modes can be visualized, as shown in Fig. 3. The figure shows the time-domain response of the DFIG active power to a step change in terminal voltage from 1 to 0.5 p.u. at $t=0 \mathrm{~s}$. The thin and thick lines are the DFIG response with and without stator dynamics, respectively. Conditions for which stator dynamics can be neglected are discussed later.

\section{Modal AnALysis-EFFeCt OF PARAMETERS}

The changes in the eigenvalues for different parameters characterizing the drive train and generator are investigated in this section. For the drive train, the effect of stiffness and inertia values are considered. For the generator, the effects of the mutual inductance and resistance values are considered.

\section{A. Drive Train Parameters}

Varying the values of stiffness and inertia while keeping all other parameters at their base-case values does not cause significant eigenvalue displacement of the electrical modes (stator

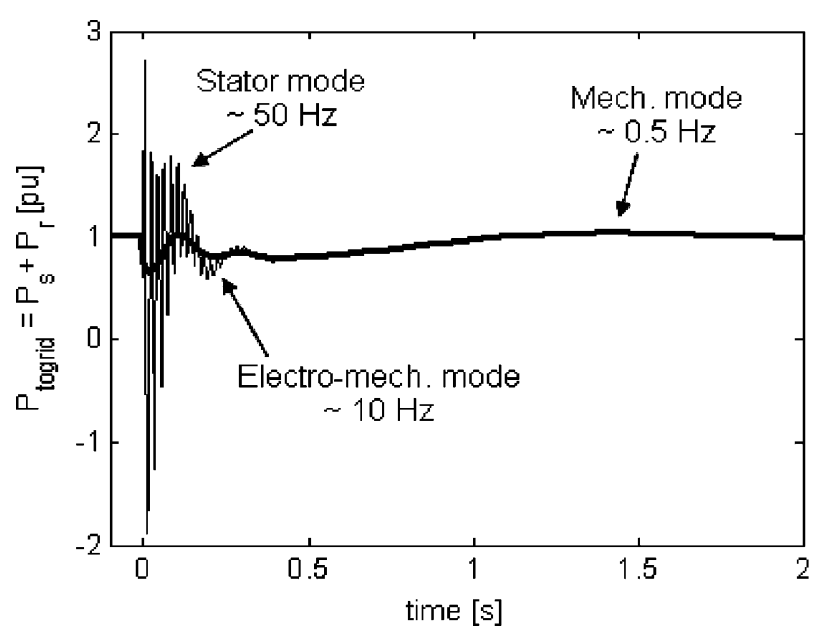

Fig. 3. Visualization of the DFIG modes in time domain: active power response to change in terminal voltage.

TABLE II

(NT) AND T MODES FOR DiFFERENT DRIVE-TRAIN PARAMETERS

(A) $\mathrm{k}=03$ pulel.rad, $\mathrm{Hg}=0.4 \mathrm{~s}, \mathrm{Ht}=4 \mathrm{~s}$

\begin{tabular}{|c|c|cc|cccc|}
\hline & $\lambda=\sigma \pm j \omega$ & $\mathbf{f}_{\text {osc }}$ & $\zeta$ & Peds' & Por & Potw & Pot \\
\hline NT & $-0.31 \pm \mathrm{j} 3.38$ & 0.54 & 0.092 & .01 & .00 & $\mathbf{. 4 8}$ & $\mathbf{. 5 0}$ \\
T & $-8.01 \pm \mathrm{j} 63.6$ & 10.12 & 0.125 & $\mathbf{. 4 7}$ & $\mathbf{. 4 6}$ & .01 & .00 \\
\hline
\end{tabular}

(B) $\mathrm{k}=50$ pujel. $\mathrm{rad}, \mathrm{Hg}=1 \mathrm{~s}, \mathrm{Ht}=1 \mathrm{~s}$

\begin{tabular}{|c|c|cc|cccc|}
\hline & $h=\boldsymbol{\sigma} \pm \mathbf{j} \boldsymbol{\omega}$ & $\mathbf{f}_{\text {osc }}$ & $\zeta$ & Peds' & Por & P9tw & Pot \\
\hline NT & $-8.23 \pm \mathrm{j} 26.4$ & 4.20 & 0.298 &. $\mathbf{4 7}$ &. $\mathbf{2 2}$ & .03 & $\mathbf{. 2 6}$ \\
$\mathbf{T}$ & $-0.48 \pm \mathrm{j} 128.6$ & 20.47 & 0.004 & .03 & .27 & .47 &. $\mathbf{2 2}$ \\
\hline
\end{tabular}

and nonoscillating modes). Hence, the following discussion describes only the effect on the mechanical and electromechanical modes.

For a two-mass drive train, the mechanical state variables contribute to two modes. One is of a lower frequency, which is the nontorsional mode (causes in-phase oscillations of inertias). The other is of a higher frequency, which is the torsional mode (causes antiphase oscillations of inertias). The mechanical parameters determine which of these two modes is dominant and whether they are mechanical or electromechanical.

For WECS with DFIG and flexible drive trains, the stiffness has a low value, and inertias are different of about one order ( $k<1$ p.u./el.rad, $H_{t} \approx 10 H_{g} \approx 0.4 \mathrm{~s}$ ) [7], [16]. In such a case, the nontorsional mode is the dominant mode, which is a mechanical mode. This is shown in Table II(A) where the lower frequency mode $(0.54 \mathrm{~Hz})$ is closest to the imaginary axis and has significant participation only from the shaft and turbine states.

For conventional SG, the stiffness is relatively higher, and inertias are of the same order $\left(k \geq 50\right.$ p.u./el.rad, $H_{t} \approx H_{g} \approx$ $1 \mathrm{~s}$ [ [7], [13]. In such a case, the torsional mode is the dominant mode, which is a mechanical mode. This is shown in Table II(B) where the higher frequency mode $(20.47 \mathrm{~Hz})$ is closest to the imaginary axis and has significant participation only from the mechanical states. In general, this mode is out of the frequency 

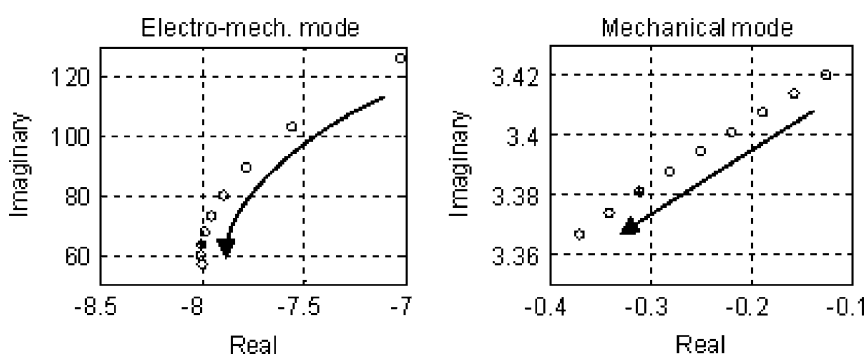

Fig. 4. Eigenvalue loci of the electromechanical and mechanical modes for increasing mutual inductance $\left(L_{m}=1-5\right.$ p.u.).

range of interest and is not considered in stability studies of low-frequency oscillations.

In Table II(B), the nontorsional mode (NT) has nearly equal participation of both the generator and the turbine. The combination of these two factors (no torsion and equal participation) means that for stiff drive train and similar generator and turbine inertia (typical for SG), the drive train behaves as a single mass for the electromechanical mode.

The same observation cannot be made for flexible shafts (typical for WECS with DFIG), as shown in Table II(A). This clearly shows that in such a case the terms "system mode," "electromechanical mode," and "nontorsional mode" cannot be used interchangeably, as it is done for conventional SG.

\section{B. Generator Parameters}

The parameters whose effects are investigated are those that present the most variability across references (see Appendix). These are the mutual inductance $L_{m}$ and the stator resistance $R_{s}$.

1) Mutual Inductance: Varying the value of $L_{m}$ while keeping all other parameters constant does not cause significant eigenvalue displacement for the electrical modes (stator and nonoscillating modes). For the electromechanical and mechanical modes, the corresponding eigenvalue displacements are shown in Fig. 4.

For both modes, the magnitude of the imaginary part decreases and that of the real part increases as $L_{m}$ increases. The mutual inductance can be seen as a representation of the airgap length, with a large inductance accounting for a small airgap. Hence, the observations indicate that small-airgap machines are better damped and their oscillation frequencies are lower compared to large-airgap machines.

2) Stator Resistance: Varying the stator resistance $R_{s}$ while keeping all other parameters constant causes noticeable displacements for all eigenvalues. Fig. 5 show the eigenvalue loci for $R_{s} / X_{m}=1 / 800$ to $1 / 100$. As the stator resistance increases, all the oscillating modes are better damped since they move further away from the imaginary axis.

The nonoscillating mode becomes more and more negative up to a point $\left(R_{s} / X_{m} \approx 1 / 120\right)$. Then, it suddenly moves back toward the origin.

The oscillation frequency decreases most noticeably for the stator mode. However, it remains out of the frequency range of interest. For the mechanical mode, the frequency drop is
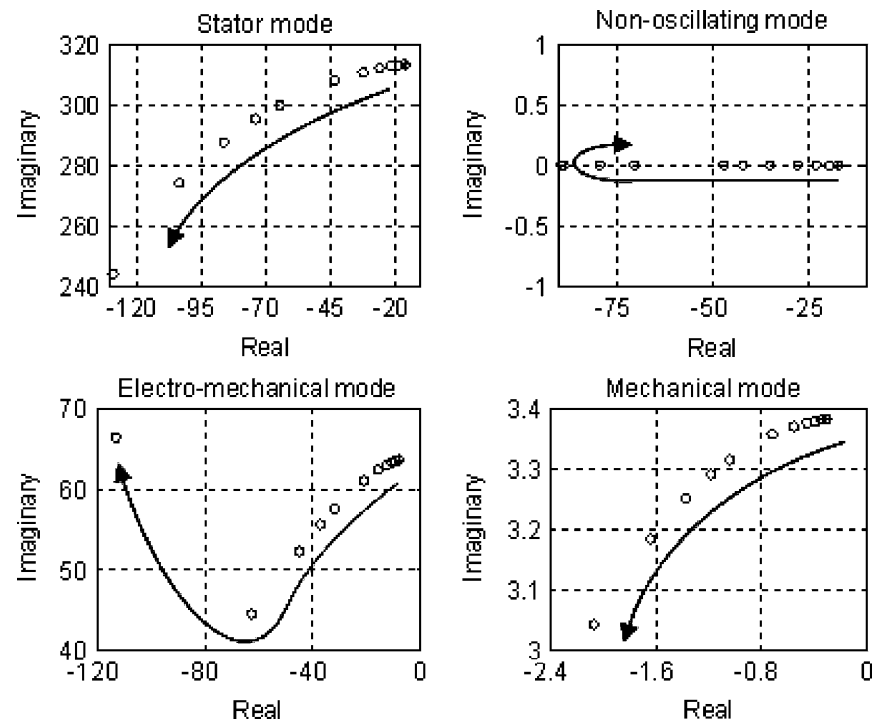

Fig. 5. Eigenvalue loci of the stator, nonoscillating, electromechanical, and mechanical modes for increasing stator resistance $\left(R_{s} / X_{m}=1 / 800\right.$ to $\left.1 / 100\right)$.

TABLE III

MOdes FOR VERY RESISTIVE MACHINE $\left(R_{s} / X_{m}=1 / 50\right)$

(A) Eigervalues $\lambda$ and nature of the mode

\begin{tabular}{|c|c|c|}
\hline & $h=\mathbf{0} \pm \mathbf{j} \mathbf{0}$ & Nature of the Mode \\
\hline$h_{1}$ & $-8.66 \pm j 4.69$ & Mecharical mode \\
\hline$h_{2}$ & $-50.61 \pm \mathrm{j} 162.09$ & Electrical roode \\
\hline$h_{3}$ & $-469.59 \pm \mathrm{j} 151.11$ & Electrical roode \\
\hline 24 & -2.60 & Mecharical mode \\
\hline
\end{tabular}

(B) Oscillation frequency $f_{o s c}[\mathrm{~Hz}]$, damping ratio $\xi$ ard participation factoss

\begin{tabular}{|c|c|c|c|c|c|c|c|c|c|}
\hline & $\mathbf{f}_{\text {ost }}$ & $\zeta$ & Piqs & Pids & Pees' & Peds' & $P_{G r}$ & Petw & Pot \\
\hline$h_{1}$ & 0.74 & 0.879 & .00 & .00 & .00 & .04 & .44 & .46 & .06 \\
\hline$h_{2}$ & 2580 & 0.298 & .13 & .12 & .35 & .38 & .02 & 00 & .00 \\
\hline$h_{3}$ & 24.05 & 0.951 & .37 & .36 & .13 & .13 & .01 & 00 & .00 \\
\hline 24 & 0 & 1 & .00 & .00 & .00 & .01 & .13 & .29 & $5 T$ \\
\hline
\end{tabular}

less pronounced (see scaling of the imaginary axis). For the electromechanical mode, the frequency decreases up to a point $\left(R_{s} / X_{m} \approx 1 / 120\right)$. Then, it increases again.

Participation factors are also affected resulting in completely different dynamics for very resistive machines $\left(R_{s} / X_{m} \geq\right.$ $1 / 100)$. In such cases, the real mode is the dominant mode (closest to the imaginary axis) as shown in Table III(A), i.e., the system is overdamped. In addition, the electrical and mechanical dynamics become decoupled as shown in Table III(B) where $\lambda_{1}$ and $\lambda_{4}$ are the mechanical modes (significant participation from mechanical states only), and $\lambda_{2}$ and $\lambda_{3}$ are the electrical modes (significant participation from electrical states only).

\section{Modal Analysis-EfFect of the Operating Point}

In this section, the effects of power production at nonsynchronous speeds, nonunity power factors, and nonunity terminal voltages are investigated. 
TABLE IV

INVESTIGATED INITIAL ROTOR SPEED AND CORRESPONDING ACTIVE POWER LEVEL

(A) Sub-synchronous speed operation $=$ MFT regime

\begin{tabular}{|l|ccccccc|}
\hline $\boldsymbol{\omega}_{\mathbf{T}}$ & 0.67 & 0.74 & 0.8 & 0.85 & 0.89 & 0.93 & 1 \\
\hline $\mathbf{P}_{\text {togidd }}$ & 0.3 & 0.4 & 0.5 & 0.6 & 0.7 & 0.8 & 1 \\
\hline
\end{tabular}

(B) Super-synchronous speed operation = CFT regime

\begin{tabular}{|l|ccccccc|}
\hline $\boldsymbol{\omega}_{\mathbf{T}}$ & 1 & 1.05 & 1.1 & 1.15 & 1.2 & 1.25 & 1.3 \\
\hline $\mathbf{P}_{\text {togaid }}$ & 1 & 1 & 1 & 1 & 1 & 1 & 1 \\
\hline
\end{tabular}

TABLE V

MODES FOR SUBSYNCHRONOUS SPEED OPERATION $\left(\omega_{r}=0.7\right.$ P.U., $P_{\text {togrid }}=0.35$ P.U. $)$

(A) Eigervalues $\lambda$ and nature of the mode

\begin{tabular}{|l|c|l|}
\hline & $\boldsymbol{h}=\mathbf{0} \pm \mathbf{j} \boldsymbol{j}$ & Nature of the Mode \\
\hline$h_{\mathbf{1}}$ & $-3.66 \pm \mathrm{j} 8.55$ & Electro-mecharical mode \\
$h_{\mathbf{2}}$ & $-12.62 \pm \mathrm{j} 112.43$ & Electro-mecharical mode \\
$h_{\mathbf{3}}$ & $-16.29 \pm \mathrm{j} 312.94$ & Stator mode \\
$h_{\mathbf{4}}$ & -1.21 & Non-oscillating mode \\
\hline
\end{tabular}

(B) Oscillation frequency $\mathrm{f}_{0 \mathrm{~s}}[\mathrm{~Hz}]$, damping ratio $\zeta$ and participation factos

\begin{tabular}{|c|c|c|c|c|c|c|c|c|c|}
\hline & $\mathbf{f}_{\text {osit }}$ & $\zeta$ & Piqs & Pids & Peqs' & $P_{\text {ede }}$ & $\mathbf{P}_{\text {OIT }}$ & Petw & Pot \\
\hline$h_{1}$ & 1.36 & 0.393 & 00 & .04 & .09 & .00 & .30 & .49 & .07 \\
\hline$h_{2}$ & 17.89 & 0.111 & .04 & .05 & .34 & .44 & .13 & .00 & .00 \\
\hline$h_{3}$ & 49.81 & 0.052 & .47 & .46 & .03 & .04 & .00 & .00 & .00 \\
\hline$h_{4}$ & 0 & 1 & .00 & .01 & .03 & .00 & .10 & .08 & .78 \\
\hline
\end{tabular}

\section{A. Initial Rotor Speed and Active Power Loading}

Since the DFIG may operate at large slips, it is important to study how its dynamic behavior changes with the rotor speed. Table IV shows the initial rotor speeds that are investigated. The sub- and supersynchronous speeds in Table IV(A) and IV(B) mean that the DFIG is in maximum power tracking (MPT) regime or constant power tracking (CPT) regime, respectively.

The effect of initial rotor speed on the stator mode is not significant. For the nonoscillating mode, the eigenvalue is the furthest away from the imaginary axis at synchronous speeds, while its absolute value decreases dramatically at nonsynchronous speeds. In fact, at large slip, the real eigenvalue is the dominant mode as shown in Table V(A) for the operating point $\omega_{r}=0.7$ p.u., $P_{\text {togrid }}=0.35$ p.u. In such a case, the system is overdamped, and the oscillations are not an issue.

Fig. 6 shows the eigenvalue displacement of the electromechanical and mechanical modes for the operating points of Table IV. From a stability viewpoint, small-slip speed (operating points around $\mathrm{B}$ ) is the region of least stability. This also means that assuming the rated speed as synchronous is a more conservative approach. For the mechanical mode, the operating points $\mathrm{A}$ and $\mathrm{C}$ are the most stable for sub- and supersynchronous speed operations, respectively. This means that in both the MPT and CPT regimes, there is an optimal speed for the stability of the critical mode.
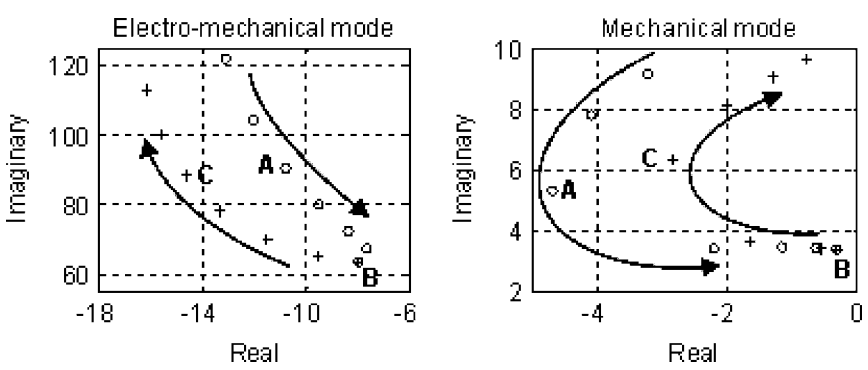

Fig. 6. Eigenvalue loci of the electromechanical and mechanical modes for increasing rotor speed $\left(\omega_{r}=0.67-1.3\right.$ p.u.). The indicated operating points are: A for $\omega_{r}=0.8$ p.u.; B for $\omega_{r}=1$ p.u.; C for $\omega_{r}=1.15$ p.u. The symbols "o" and "+" are used for sub- and supersynchronous speeds, respectively.
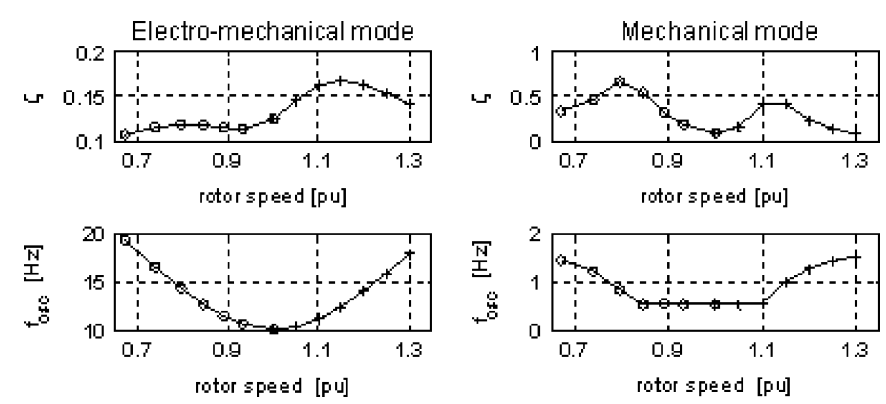

Fig. 7. Damping ratio and oscillation frequency of the electromechanical and mechanical modes for increasing rotor speed ( $\omega_{r}=0.67-1.3$ p.u.).

Fig. 7 shows the damping ratio and frequency of the electromechanical and mechanical modes as functions of the initial speeds given in Table IV. The damping ratio as well as the frequency have values around the synchronous speed. Interestingly, if the slip range is limited to $\pm 10 \%$, the change in $\zeta$ and $f_{\text {osc }}$ is also limited to $\pm 10 \%$.

Participation factors are also modified. At nonsynchronous speeds, the contribution of electrical dynamics is more important for the complex eigenvalues (oscillating modes). For the real eigenvalue (nonoscillating mode), it is the contribution of mechanical dynamics that becomes most important. These observations can be seen in Table V.

\section{B. Initial Reactive Power Loading}

The reactive power level does not influence the small-signal properties significantly. This is shown in Table VI where the changes in eigenvalues for $Q_{\text {togrid }}=-1$ p.u. (reactive power absorption at power factor 0.7 ), $Q_{\text {togrid }}=0$ p.u. (unity power factor operation, base case), and $Q_{\text {togrid }}=1$ p.u. (reactive power production at power factor 0.7) are not important. Participation factors are not shown as they are not significantly modified. The main effect of the DFIG reactive power level consists in higher current levels for nonunity power factor, as shown in Table VII.

\section{Initial Terminal Voltage}

The effect of voltage level is different in CPT and MPT conditions. Fig. 8 shows the eigenvalue displacement for increasing terminal voltages in the CPT regime $\left(P_{\text {togrid }}=1\right.$ p.u. 
TABLE VI

MODES FOR DIFFERENT REACTIVE POWER LEVELS WITH $P_{\text {togrid }}=1$ P.U., $V_{s}=1$ P.U.

(A) Eigervalues $\lambda=\sigma \pm j \omega$

\begin{tabular}{|c|c|c|c|}
\hline & $Q_{\text {togid }}=-1$ pu & $Q_{\text {toprid }}=0 \mathrm{pu}$ & $Q_{\text {topaid }}=1 \mathrm{pu}$ \\
\hline$h_{1}$ & $-0.34 \pm \mathrm{j} 3.37$ & $-0.31 \pm j \quad 3.38$ & $-0.29 \pm$ j 3.39 \\
\hline$h_{2}$ & $-8.04 \pm j 60.40$ & $-8.01 \pm j 63.57$ & $-7.96 \pm \mathrm{j} 66.59$ \\
\hline 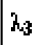 & $-16.09 \pm \mathrm{j} 313.30$ & $-16.16 \pm \mathrm{j} 313.31$ & $-16.23 \pm j 313.31$ \\
\hline$h_{4}$ & -17.45 & -17.44 & -17.44 \\
\hline
\end{tabular}

(B) Oscillation frequency $\mathrm{f}_{\mathrm{osc}}[\mathrm{Hz}]$ and darmping ratio $\zeta$

\begin{tabular}{|l|cc|cc|cc|}
\hline & \multicolumn{2}{|c|}{$Q_{\text {togrid }}=-\mathbf{l} \mathbf{p u}$} & \multicolumn{2}{c|}{$Q_{\text {togrid }}=\mathbf{0} \mathbf{p u}$} & \multicolumn{2}{c|}{$Q_{\text {togrid }}=\mathbf{l ~ p u}$} \\
& $\mathbf{f}_{\text {osc }}$ & $\zeta$ & $\mathbf{f}_{\text {osc }}$ & $\zeta$ & $\mathbf{f}_{\text {ost }}$ & $\zeta$ \\
\hline$h_{\mathbf{1}}$ & 0.54 & 0.010 & 0.54 & 0.092 & 0.54 & 0.086 \\
$h_{\mathbf{1}}$ & 9.61 & 0.132 & 10.12 & 0.125 & 10.60 & 0.119 \\
$h_{\mathbf{3}}$ & 49.86 & 0.051 & 49.86 & 0.052 & 49.86 & 0.052 \\
$h_{4}$ & 0 & 1 & 0 & 1 & 0 & 1 \\
\hline
\end{tabular}

TABLE VII

MAgNitude OF STATOR AND ROTOR CURRENT FOR DifFERENT REACTIVE POWER LEVELS WITH $P_{\text {togrid }}=1$ P.U., $V_{s}=1$ P.U.

\begin{tabular}{|l|c|c|c|}
\hline & Qtogrid $_{\text {to }}=-\mathbf{~ p u}$ & Qtogrid $_{\text {p }}=\mathbf{0} \mathbf{~ p u}$ & Q $_{\text {togrid }}=\mathbf{l} \mathbf{~ p u}$ \\
\hline $\mathbf{I}_{\mathbf{s}}$ & 1.42 & 1.01 & 1.42 \\
$\mathbf{I}_{\mathbf{r}}$ & 1.27 & 1.05 & 1.62 \\
\hline
\end{tabular}
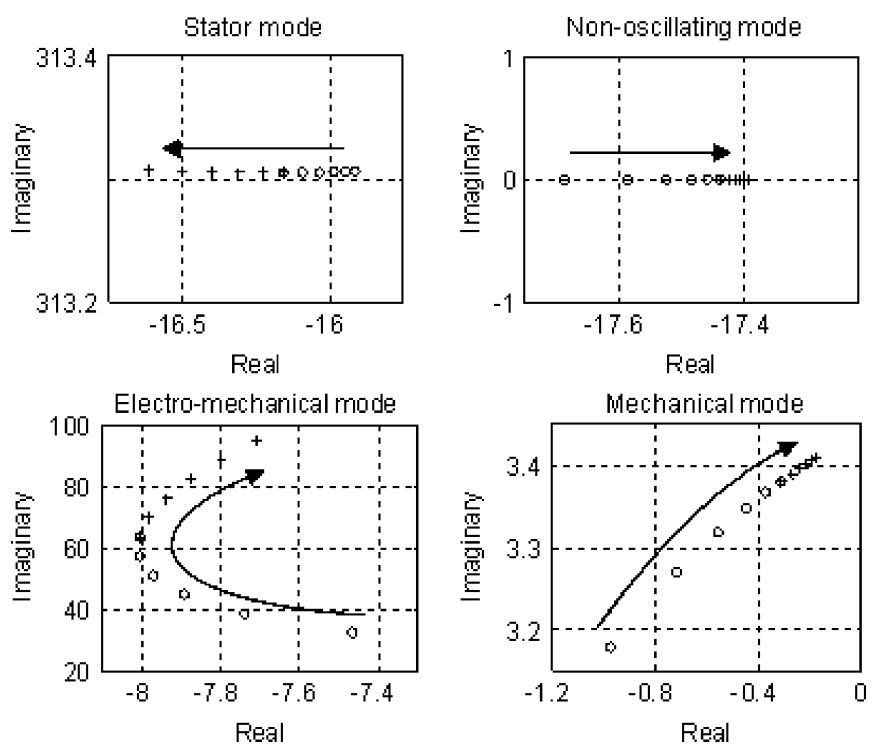

Fig. 8. Eigenvalue loci for increasing terminal voltage $\left(V_{s}=0.5-1.5\right.$ p.u. $)$ with $P_{\text {togrid }}=1$ p.u., $Q_{\text {togrid }}=0$ p.u. The symbols "o" and "+" are used for voltages below and above unity, respectively.

and $\omega_{r}=\omega_{s}$ ). The stator and the nonoscillating modes are not significantly affected. For both electromechanical and mechanical modes, the oscillation frequency increases with the voltage as the magnitude of the imaginary part increases. In the CPT regime, the system is less stable for the overvoltage condition as the dominant mode (mechanical mode) moves closer to the imaginary axis.
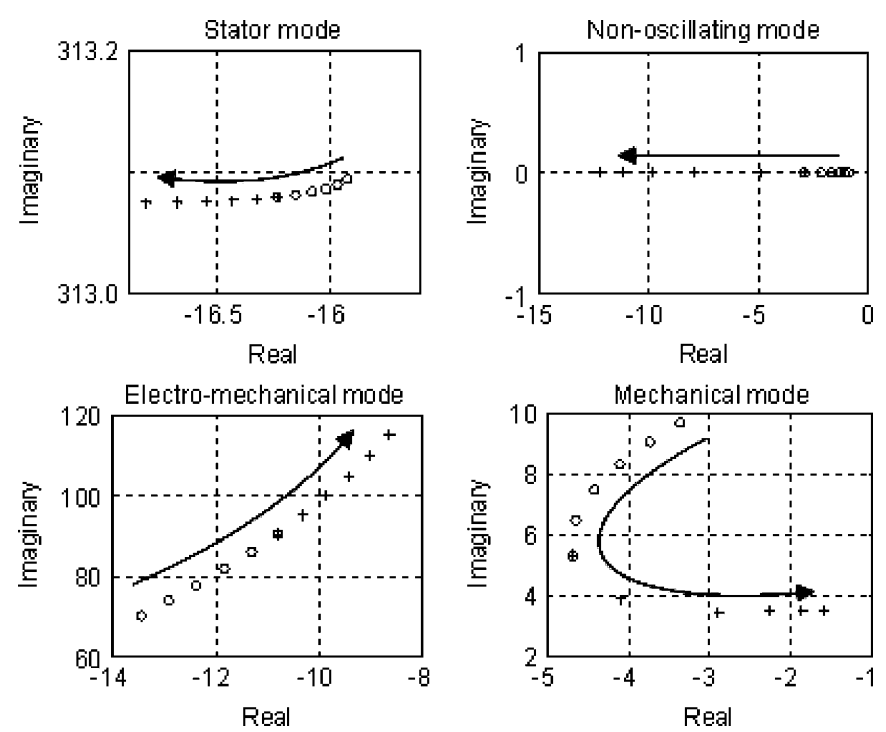

Fig. 9. Eigenvalue loci for increasing terminal voltage $\left(V_{s}=0.5-1.5\right.$ p.u. $)$ with $P_{\text {togrid }}=0.5 \mathrm{pu}, Q_{\text {togrid }}=0$ p.u. The symbols "o" and "+" are used for voltages below and above unity, respectively.
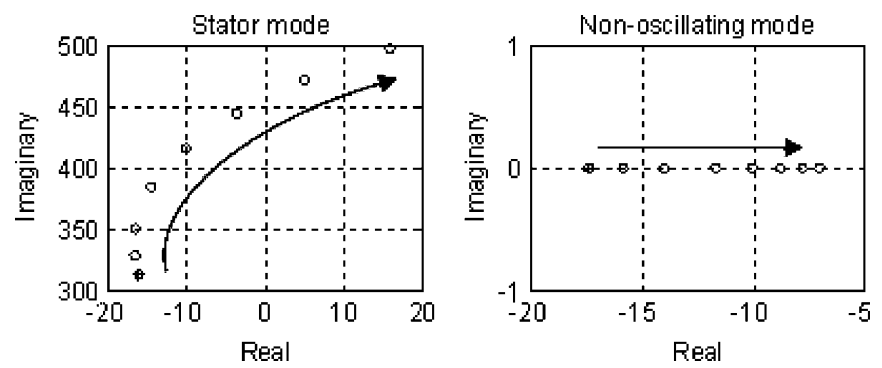

Fig. 10. Eigenvalue loci of the stator and nonoscillating modes for different values of external reactance ( $X_{e}=0-0.15$ p.u.).

TABLE VIII

INVESTIGATED VALUES of EXTERNAL LINE REACTANCE $X_{e}$ [P.U.]

\begin{tabular}{|l|llllllll|}
\hline $\mathrm{X}_{\mathrm{e}}$ & 0 & 0.01 & 0.025 & 0.05 & 0.075 & 0.1 & 0.125 & 0.15 \\
\hline
\end{tabular}

Fig. 9 shows the eigenvalue displacement for increasing terminal voltages in the MPT regime $\left(P_{\text {togrid }}<1\right.$ p.u. and $\left.\omega_{r}<\omega_{s}\right)$. The stator mode is not significantly affected. The electromechanical and mechanical modes move toward the imaginary axis in an overvoltage condition indicating a less stable condition. For the depressed voltage condition $\left(V_{s} \leq 0.5\right.$ p.u. $)$, the system is overdamped.

\section{Modal ANAlysis-EFfect OF GRID StRENGTH}

In earlier discussion, the stator voltage was assumed constant, i.e., the external grid is infinitely strong. If, however, the DFIG is connected to the infinite bus through a finite reactance, the terminal voltage is not constant and becomes an algebraic variable, which has to be eliminated as in (20).

For the external line reactance values of Table VIII, the effect of $X_{e}$ is only significant for the stator and the nonoscillating modes. Fig. 10 shows the corresponding eigenvalue displacement. Both modes move toward the right-half plane as $X_{e}$ 
increases (i.e., as the external grid is weaker). For too large a line reactance, the stator mode becomes unstable, requiring a closed-loop control or series compensation to reduce the effective value of $X_{e}$.

Grid strength does not affect the participation factors significantly. As a result, although frequency and damping change, the stator mode remains decoupled from the other modes.

\section{NEGLECTING StATOR TRANSIENT}

For conventional SG, the stator dynamics is neglected for compatibility and simplification purposes. This assumption is acceptable as it gives conservative results (speed deviation is overestimated) [13]. A recent paper showed similar conclusions for the DFIG with time-domain simulations [17].

In this paper, the validity of neglecting stator dynamics is examined with modal analysis. Stator state variables can be considered as algebraic variables (i.e., they change instantaneously) when the stator mode has a small time constant (eigenvalue with large real-part magnitude), high frequency that is out of the range of interest (eigenvalue with large imaginary-part magnitude), and when the stator states participate significantly only in the stator mode (if stator states participate in other modes, neglecting stator dynamics may modify these modes).

In all the cases discussed earlier, the above three conditions were fulfilled. In fact, it is only in extreme cases that the participation of stator states in other modes becomes significant. In this paper, the stator states participate significantly in other modes $\left(p_{\text {iqs }}+p_{\text {ids }} \geq 10 \%\right)$ when $H_{t} \leq 1.3 \mathrm{~s}, L_{m} \leq 1$ p.u., and $R_{s} / X_{m} \geq 1 / 125$. In other words, for machines with sufficiently high inertia, high magnetizing inductance, and small stator resistance, neglecting stator transient does not modify the dynamics of interest.

\section{CONCLUSION}

This paper presented the modal analysis of an SMIB system with DFIG. A seventh-order model has been used with four state variables for the DFIG (stator and rotor dynamics) and three for the drive train (two-mass model). The results give the machine local modes, i.e., oscillations of the DFIG against the external system.

The small-signal behavior is characterized by four modes, three of which are oscillating. The slowest mode (which is the dominant mode) is the drive-train nontorsional mode. Oscillating at $\sim 0.5 \mathrm{~Hz}$, it is a mechanical mode associated with shaft and turbine dynamics. The second slowest mode is the drive-train torsional mode. Oscillating at $\sim 10 \mathrm{~Hz}$, it is an electromechanical mode associated with rotor dynamics (generator speed and rotor $\mathrm{q}$-axis flux). The third oscillating mode is an electrical mode. Oscillating at $\sim 50 \mathrm{~Hz}$, it is associated with the stator dynamics. The nonoscillating mode has a small time constant of $\sim 0.05 \mathrm{~s}$ and is associated with the rotor d-axis flux dynamics.

The effects of several parameters (drive-train inertias, stiffness, generator mutual inductance, and stator resistance), operating points (rotor speed, reactive power loading, and terminalvoltage level), and grid strength (external line reactance value) on the system modes have been studied. The conditions for
TABLE IX

Two-Mass Drive-Train PARAMETERs From [16] AND [7]

\begin{tabular}{|l|ccc|}
\hline Reference & Hg [s] & Ht [s] & keq [pw/el.rad] \\
\hline [Ack05] p545 & $0.4 * 0.8$ & $2.0 * 6.0$ & $0.3 * 0.6$ \\
[Hir82] & 0.5 & 12.5 & 0.15 \\
\hline
\end{tabular}

TABLE X

DFIG PARAMETERS FROM [9], [18], [19], [20], AND [21]

\begin{tabular}{|l|ccc|cccc|}
\hline Ref & $\mathbf{P}_{\mathbf{r a t e d}}$ & $\mathbf{V}_{\mathbf{L L}}$ & $\mathbf{X}_{\mathbf{m}}$ & $\mathbf{R}_{\mathbf{s}} / \mathbf{X}_{\mathbf{m}}$ & $\mathbf{R}_{\mathbf{r}} / \mathbf{R}_{\mathbf{s}}$ & $\mathbf{L}_{\mathbf{s s}} / \mathbf{L}_{\mathbf{m}}$ & $\mathbf{L}_{\mathbf{I I}} / \mathbf{L}_{\mathbf{s s}}$ \\
\hline [Pap97] & .09 & 380 & 1.57 & $1 / 48$ & 0.6157 & 1.05 & 1 \\
[Led99] & .66 & $\mathrm{NA}$ & 4.1 & 11527 & 1.0526 & 1.0193 & 1.0766 \\
[Ho103] & 2 & 690 & 3.95 & $1 / 810$ & 1.125 & 1.0234 & 1.0018 \\
[Slo01] & 2 & NA & 3 & $1 / 300$ & 1 & 1.0333 & 0.9935 \\
[WMe03] & 2 & 690 & 3.3 & $1 / 475$ & 1.3071 & 1.0246 & 1.0055 \\
\hline
\end{tabular}

$\mathrm{P}_{\text {rated }}$ is in [MW], $\mathrm{X}_{\mathrm{m}}$ is in [pu], $\mathrm{V}_{\mathrm{LLs}}$ is the stator line-to-line voltage in [V]

TABLE XI

BASE-CASE DFIG PARAMETERS

\begin{tabular}{|l|l|l|}
\hline Turbine & \multicolumn{1}{|c|}{ Drive train } & \multicolumn{1}{|c|}{ DFIG } \\
\hline \multirow{3}{*}{$\mathrm{P}_{\mathrm{t}}=1 \mathrm{pu}$} & $\mathrm{k}=0.3$ pujel.mad & $\mathrm{V}_{\mathrm{s}}=1 \mathrm{pu} \quad \mathrm{X}_{\mathrm{m}}=4 \mathrm{pu}$ \\
& $\mathrm{c}=0$ & $\mathrm{R}_{\mathrm{s}}=\mathrm{X}_{\mathrm{m}} / 800 \quad \mathrm{~L}_{\mathrm{ss}}=1.01 \mathrm{~L}_{\mathrm{m}}$ \\
& $\mathrm{H}_{\mathrm{t}}=4 \mathrm{~s} \quad \mathrm{H}_{\mathrm{g}}=0.1 \mathrm{H}_{\mathrm{t}}$ & $\mathrm{R}_{\mathrm{r}}=1.1 \mathrm{R} \quad \mathrm{L}_{\mathrm{II}}=1.005 \mathrm{~L}_{\mathrm{ss}}$ \\
\hline
\end{tabular}

which stator dynamics can be neglected have also been provided.

The results of this study offer a good starting point for the small-signal analysis of multimachine power systems with both conventional SG and wind-driven DFIG.

\section{APPENDIX}

\section{A. DFIG Parameters}

Table IX gives some values for the generator inertia $H_{g}$, turbine inertia $H_{t}$ and equivalent shaft stiffness $k_{e q}$ of the twomass drive train model. Both references consider MW machines. The smaller values of $H_{t}$ given in [16] can be explained by the use of lighter material for blade fabrication nowadays.

Table $\mathrm{X}$ gives some values for induction machine parameters. For consistent comparison, values are expressed in terms of the ratio. The columns $X_{m}$ and $R_{s} / X_{m}$ present the largest variability. Roughly said, larger machines have larger $X_{m}$ and smaller $R_{s} / X_{m}$.

Table XI gives the parameters used for the base case.

\section{B. Definitions for Modal Analysis}

For the eigenvalues $\lambda=\sigma \pm j \omega$ of the matrix $A_{\text {sys }}$ defined in (20), the oscillation frequency $f_{\text {osc }}[\mathrm{Hz}]$, damping ratio $\zeta$, and participation factors $p_{k i}$ can be calculated as

$$
\begin{aligned}
f_{o s c} & =\omega /(2 \pi) \\
\zeta & =-\sigma / \sqrt{\sigma^{2}+\omega^{2}} \\
p_{k i} & =\left|\Psi_{i k}\right|\left|\Phi_{k i}\right| / \sum_{k=1}^{n}\left|\Psi_{i k}\right|\left|\Phi_{k i}\right|
\end{aligned}
$$


where $\Psi_{i k}$ and $\Phi_{k i}$ are the $k$ th elements of the left and right eigenvectors of the $i$ th mode. In (23), normalization is done so that $p_{k i}$ is the participation percentage of the $k$ th state variable in the $i$ th eigenvalue.

\section{REFERENCES}

[1] V. Akhmatov, "Analysis of dynamic behaviour of electric power systems with large amount of wind power" Ph.D. dissertation, Tech. Univ. Denmark, Lyngby, Denmark, 2003.

[2] J. G. Slootweg, "Wind power modelling and impact on power systems dynamics" Ph.D. dissertation, Delft Univ. Technol., Delft, The Netherlands, 2003.

[3] R. S. Pena, "Vector control strategies for a doubly-fed induction generator driven by a wind turbine" Ph.D. dissertation, Univ. Nottingham, Nottingham, U.K., 1996.

[4] M. V. A. Nunes, J. A. P. Lopes, H. H. Zurn, U. H. Bezerra, and R. G. Almeida, "Influence of the variable-speed wind generators in transient stability margin of the conventional generators integrated in electrical grids," IEEE Trans. Energy Convers., vol. 19, no. 4, pp. 692-701, Dec. 2004.

[5] J. Morren and S. W. H. de Haan, "Ridethrough of wind turbines with doubly-fed induction generator during a voltage dip," IEEE Trans. Energy Convers., vol. 20, no. 2, pp. 435-441, Jun. 2005.

[6] F. M. Hughes, O. Anaya-Lara, N. Jenkins, and G. Strbac, "Control of DFIG-based wind generation for power network support," IEEE Trans. Power Syst., vol. 20, no. 4, pp. 1958-1966, Nov. 2005.

[7] E. N. Hinrichsen and P. J. Nolan, "Dynamics and stability of wind turbine generators," IEEE Trans. Power App. Syst., vol. PAS-101, no. 8, pp. 26402648, Aug. 1982.

[8] M. G. Ioannides, "Doubly fed induction machine state variables model and dynamic response," IEEE Trans. Energy Convers., vol. 6, no. 1, pp. 55-61, Mar. 1991.

[9] S. A. Papathanassiou and M. P. Papadopoulos, "State-space modelling and eigenvalue analysis of the slip energy recovery drive," Proc. Inst. Elect. Eng. Electric Power Applications, vol. 144, no. 1, pp. 27-36, Jan. 1997.

[10] H. Snel, "Review of the present status of rotor aerodynamics," Wind Energy, vol. 1, no. 1, pp. 46-69, Jan. 1999.

[11] T. Petru and T. Thiringer, "Modeling of wind turbines for power system studies," IEEE Trans. Power Syst., vol. 17, no. 4, pp. 1132-1139, Nov. 2002.

[12] J. Wilkie, W. E. Leithead, and C. Anderson, "Modelling of wind turbine by simple models," Wind Eng., vol. 14, no. 4, pp. 247-274, Jul. 1990.

[13] P. Kundur, Power System Stability and Control. New York: McGrawHill, 1994.

[14] S. K. Salman and A. L. J. Teo, "Windmill modeling consideration and factors influencing the stability of a grid-connected wind power-based embedded generator," IEEE Trans. Power Syst., vol. 18, no. 2, pp. 793802, May 2003.

[15] N. J. Wheeler, H. Zhang, and D. A. Grant, "Minimisation of reactive component values in back-to-back converters," in Proc. Power Electronics and Variable-Speed Drives Int. Conf., Oct. 1994, pp. 240-245.
[16] T. Ackermann, Wind Power in Power Systems. New York: Wiley, 2005.

[17] P. Ledesma and J. Usaola, "Effect of neglecting stator transients in doubly fed induction generators models," IEEE Trans. Energy Convers., vol. 19, no. 2, pp. 459-461, Jun. 2004.

[18] P. Ledesma, J. Usaola, J. L. Rodriguez, and J. C. Burgos, "Comparison between control systems in a doubly fed induction generator when connected to an electric grid," presented at the European Wind Energy Conf., vol. 1, Nice, France, Apr. 1999.

[19] L. Holdsworth, X. G. Wu, J. B. Ekanayake, and N. Jenkins, "Comparison of fixed speed and doubly-fed induction wind turbines during power system disturbances," Proc. Inst. Elect. Eng. Generation, Transmission, and Distribution, vol. 150, no. 3, pp. 343-352, May 2003.

[20] J. G. Slootweg, H. Polinder, and W. L. Kling, "Dynamic modelling of a wind turbine with doubly fed induction generator," in Proc. IEEE Power Engineering Soc. Summer Meeting, Jul. 2001, vol. 1, pp. 644-649.

[21] P. V. Meirhaeghe. (2003). Double fed induction machine: An Eurostag model. [Online]. Available: http://www.eurostag.be

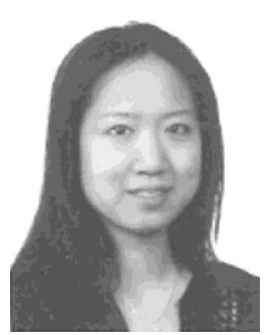

Francoise Mei (S'04) was born in Belgium in 1981. She received the Graduate degree in electromechanical engineering from the Catholic University of Leuven, Leuven, Belgium, in 2004. Currently, she is working toward the Ph.D. degree at the Imperial College London, London, U.K.

Her current research interests include distributed generation modeling and control.

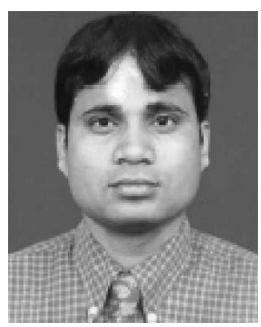

Bikash Pal (M'00-SM'02) received the B.E.E. (with honors) degree from Jadavpur University, Calcutta, India, the M.E. degree from the Indian Institute of Science, Bangalore, India, and the Ph.D. degree from the Imperial College London, London, U.K., in 1990, 1992, and 1999, respectively, all in electrical engineering.

Currently, he is a Senior Lecturer in the Department of Electrical and Electronic Engineering, Imperial College London. His current research interests include power system dynamics and flexible ac trans- 